\title{
Monte-Carlo Code (MCNP) Modeling Of The Advanced Test Reactor Applicable To The Mixed Oxide (MOX) Test Irradiation
}

G. S. Chang

R. C. Pederson

July 2005

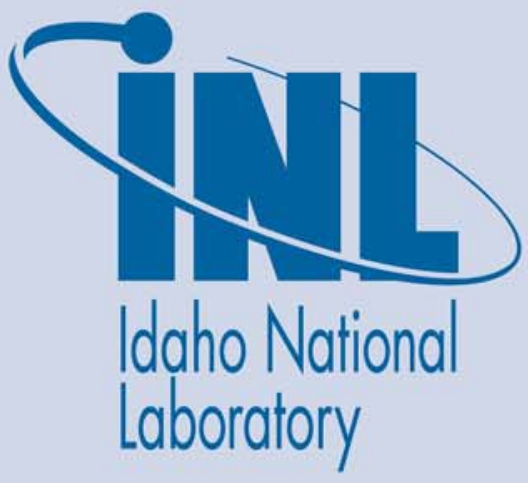

The INL is a U.S. Department of Energy National Laboratory operated by Battelle Energy Alliance 


\title{
Monte-Carlo Code (MCNP) Modeling of the Advanced Test Reactor Applicable to the Mixed Oxide (MOX) Test Irradiation
}

\author{
G. S. Chang and R. C. Pederson
}

July 2005

\author{
Idaho National Laboratory \\ Idaho Falls, Idaho 83415
}

Prepared for the

U.S. Department of Energy

Fissile Materials Disposition Program

Under DOE Idaho Operations Office

Contract DE-AC07-05ID12417 



\begin{abstract}
Mixed oxide (MOX) test capsules prepared with weapons-derived plutonium have been irradiated to a burnup of $50 \mathrm{GWd} / \mathrm{t}$. The MOX fuel was fabricated at Los Alamos National Laboratory by a master-mix process and has been irradiated in the Advanced Test Reactor (ATR) at the Idaho National Laboratory (INL). Previous withdrawals of the same fuel have occurred at 9, 21, 30, and $40 \mathrm{GWd}$ /t. Oak Ridge National Laboratory (ORNL) manages this test series for the Department of Energy's Fissile Materials Disposition Program (FMDP).

The fuel burnup analyses presented in this study were performed using MCWO, a welldeveloped tool that couples the Monte Carlo transport code MCNP with the isotope depletion and buildup code ORIGEN-2. MCWO analysis yields time-dependent and neutron-spectrum-dependent minor actinide and $\mathrm{Pu}$ concentrations for the ATR small I-irradiation test position.

The purpose of this report is to validate both the Weapons-Grade Mixed Oxide (WG-MOX) test assembly model and the new fuel burnup analysis methodology by comparing the computed results against the neutron monitor measurements.
\end{abstract}





\section{CONTENTS}

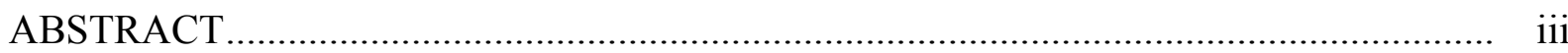

1. INTRODUCTION ...................................................................................

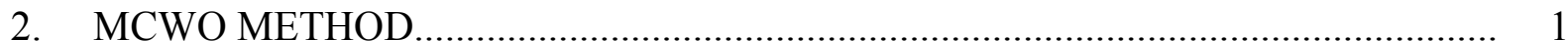

3. WG-MOX FUEL TEST ASSEMBLY MODEL .................................................. 2

4. VALIDATION OF WG-MOX FUEL TEST ASSEMBLY MODEL ......................... 4

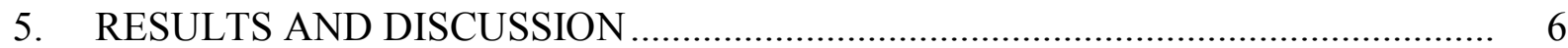

5.1 MCWO-calculated Burnup during Phase-I Irradiation .................................... 8

5.2 MCWO-calculated Burnup during Phase-II Irradiation .................................. 8

5.3. MCWO-calculated Burnup during Phase-III (Part-1) Irradiation....................... 9

5.4. MCWO-calculated Burnup during Phase-III (Part-2) Irradiation...................... 10

5.5 MCWO-calculated Burnup during Phase-IV (Part-1) Irradiation ...................... 11

5.6 MCWO-calculated Burnup during Phase-IV (part-2 and -3) Irradiation............. 12

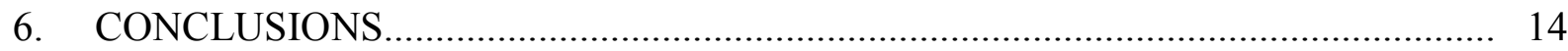

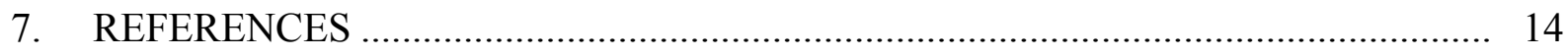

\section{FIGURES}

1. Radial cross-sectional view of the full core MCNP model with two test

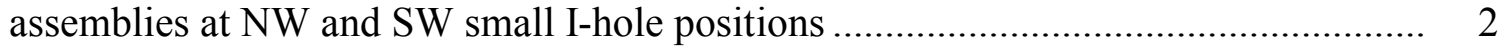

2. Detailed radial cross-sectional view of the WG-MOX fuel test assembly ................. 3

3. Measured channel Y thermal and fast neutron fluxes (ATR Cycle 115-C)................ 4 


\section{CONTENTS (continued)}

\section{TABLES}

1. Comparison of MCNP-Calculated and Measured Thermal and Fast Neutron Fluxes at Small I-24 Position (ATR Cycle 115-C)

2. ATR power history from 1 st irradiation Cycle-115C to final Cycle-132C ................. 7

3. MCWO-calculated burnup of the Phase-I MOX fuel capsules in the I-24 position of ATR from Cycle 115C to Cycle 117B (at the end of each irradiation Cycle)

4. MCWO-calculated burnup of the Phase-II MOX fuel capsules in the I-24 position of ATR from Cycle 118A to Cycle 120A (at the end of each irradiation Cycle)

5. MCWO-calculated burnup of the phase-III MOX fuel capsules in the I-24 position of ATR from Cycle 120C to Cycle 122C

6. Burnup of the Phase-III, Part-2 MOX fuel capsules in the I-24 position of ATR from Cycle 122C through Cycle 124A

7. Burnup $(\mathrm{GWd} / \mathrm{t})$ of the Phase-IV, Part-1A MOX fuel capsules in the NW I-24 position of ATR at the end of irradiation Cycle s from 124C to 126A

8. Burnup (GWd/t) of the Phase-IV, Part-1B MOX fuel capsules in the SW I-23 position (except high PALM Cycle 127B) of ATR at the end of irradiation Cycle s from 127A to $127 \mathrm{C}$

9. Burnup (GWd/t) of the Phase-IV, Part-2 MOX fuel capsules in the SW I-23 position of ATR at the end of irradiation Cycles from $127 \mathrm{C}$ to $129 \mathrm{~B}$

10. MCWO-calculated burnup of Phase-4 Part-3 MOX fuel capsules in the I-23 position of ATR from Cycle 130A to Cycle 132C 


\section{Monte-Carlo Code (MCNP) Modeling of the Advanced Test Reactor Applicable to the Mixed Oxide (MOX) Test Irradiation}

\section{INTRODUCTION}

The United States Department of Energy (DOE) Fissile Materials Disposition Program (FMDP) is pursuing methods of disposing surplus weapons-usable plutonium. One of the disposal methods being considered is irradiation of plutonium as a fissile constituent in Mixed Oxide (MOX) fuel for use by U.S. commercial light water reactors (LWR).

Given the last four decades of research, development, and deployment of MOX programs performed primarily in Europe, a large database of MOX fuel irradiation experience and knowledge already exists. Most of this experience and knowledge was gained using reactorgrade (RG) plutonium, derived from spent low-enriched uranium fuel (LWR fuel). Weaponsgrade (WG)-MOX fuel differs from the commercial fuel utilized in the European programs in that its initial fissile inventory is comprised of a higher proportion of ${ }^{239} \mathrm{Pu}$, with smaller contingents of the higher plutonium isotopes, which may be accompanied by small amounts of gallium as an impurity. At present, irradiation testing conducted in the Advanced Test Reactor (ATR) at the Idaho National Laboratory (INL) supports the disposition mission by demonstrating that the introduction of WG plutonium does not compromise the applicability of the existing RGMOX database of experience and knowledge.

Since 1998, irradiation testing of WG-MOX fuel, prepared with WG plutonium (fabricated at Los Alamos National Laboratory by a master-mix process), has been conducted in the ATR. One of the irradiation tests performed in the ATR was an experiment to support the potential licensing of MOX fuel for use in U. S. LWR. The uninstrumented test assembly included nine WG-MOX fuel capsules and neutron monitor wires. The irradiated test assembly achieved a burnup of $50 \mathrm{GWd} / \mathrm{t}$.

\section{MCWO METHOD}

In general, reactor physics analysis consists of multistep analysis methods. The multigroup diffusion equation with node-wise constant cross sections requires the fuel assembly to be appropriately homogenized. However, the complex spectral transitions in the WG-MOX fuel pellet present a serious challenge. The major source of uncertainty in the fuel burnup calculation comes from burnup-dependent cross-section (XS) and resonance treatment of neutron fluxes in the MOX fuel pellet. To avoid these problems, a validated depletion tool was developed and used in the fuel burnup analysis.

The MCNP code ${ }^{1}$ was developed by the X-6 division at Los Alamos National Laboratory as a general-purpose Monte Carlo neutron transport simulation. MCNP can model extremely complex 3-dimensional geometry, because it is only limited by the computer memory capacity and the time necessary to run such models to achieve the desired uncertainty band. MCNP uses 
continuous pointwise cross-section data evaluated from the ENDF/B-V library, and all neutron and photon reactions included in the library are accounted for in MCNP calculations.

As computational power continues to increase, it becomes more practical to utilize Monte Carlo methods to perform burnup calculations. The UNIX Bourne Again SHell (BASH) script CMO developed at the Idaho National Laboratory (INL), couples the Monte Carlo transport code $\underline{M}$ CNP with the depletion and buildup code $\underline{\mathrm{ORIGEN}-2^{2}}$ (CMO). The Monte Carlo burnup analysis methodology used in this paper consists of MCNP coupling through $\underline{\mathrm{CMO}} \underline{\text { with }}$ ORIGEN-2 $\left(\mathrm{MCWO}^{3,4}\right)$. The primary functions of MCNP are to calculate one-group cross-sections and fluxes (used by ORIGEN-2 in burnup calculations) and provide requested criticality and neutron economy information. After burnup calculations are performed by ORIGEN-2, CMO passes isotopic compositions of materials back to MCNP to begin another burnup cycle. Applying this capability allows calculation of detailed nuclide concentration and power distributions within the MOX capsule as a function of burnup.

\section{WG-MOX FUEL TEST ASSEMBLY MODEL}

The MOX fuel test assembly consists of three axial sections. Each axial section contains three fuel capsules, for a total of nine fuel capsules in one test assembly. The middle section is centered at the core midplane. All nine fuel capsules are included in the ATR MCNP Core Model. The ATR MCNP Core Model is shown in Figure 1.

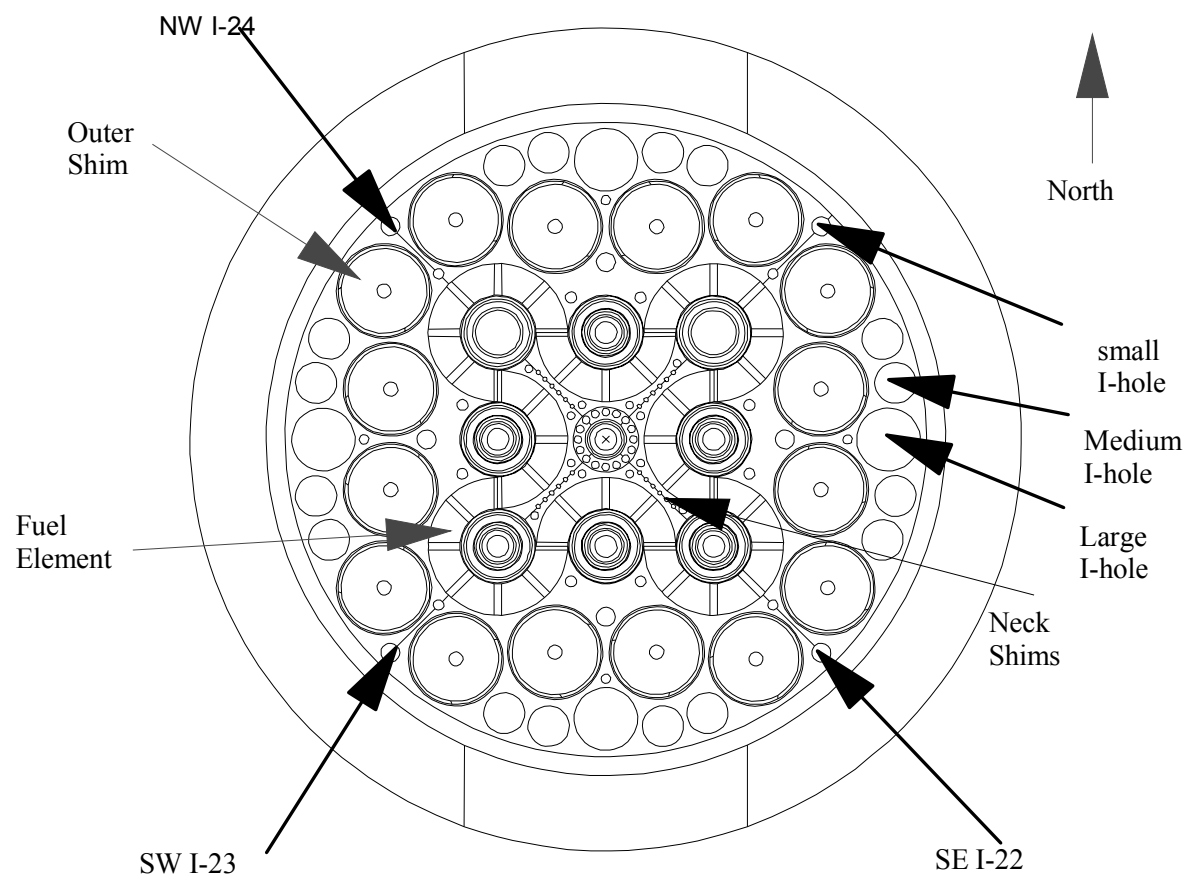

Figure 1. Radial cross-sectional view of the full core MCNP model with two test assemblies at NW and SW small I-hole positions. 
The WG-MOX test fuel pellet is comprised of five percent $\mathrm{PuO}_{2}$ and $95 \%$ depleted $\mathrm{UO}_{2}$. The fuel capsule is $0.415 \mathrm{~cm}$ in radius and $15.24 \mathrm{~cm}$ in length and each of the nine fuel capsules contains fifteen MOX fuel pellets. The capsules in channel 1 are located the farthest away from the ATR core center. The capsules in channels 2 and 3 are closer to the ATR core center. Three flux wire holders, each with Co and Ni wires are included in the WG-MOX fuel test assembly. Channel X contains the flux-wire closest to the ATR core center, and the flux wires in channels $\mathrm{Y}$ and $\mathrm{Z}$ are farthest from the ATR core center. The details are shown in Figure 2.

The validated MCWO method was used to perform the neutronics analysis of WG-MOX fuel in the ATR. The prediction of nuclide profiles and burnup distributions in irradiated MOX fuel pellets via this new methodology provided valuable data for the MOX fuel performance evaluation.

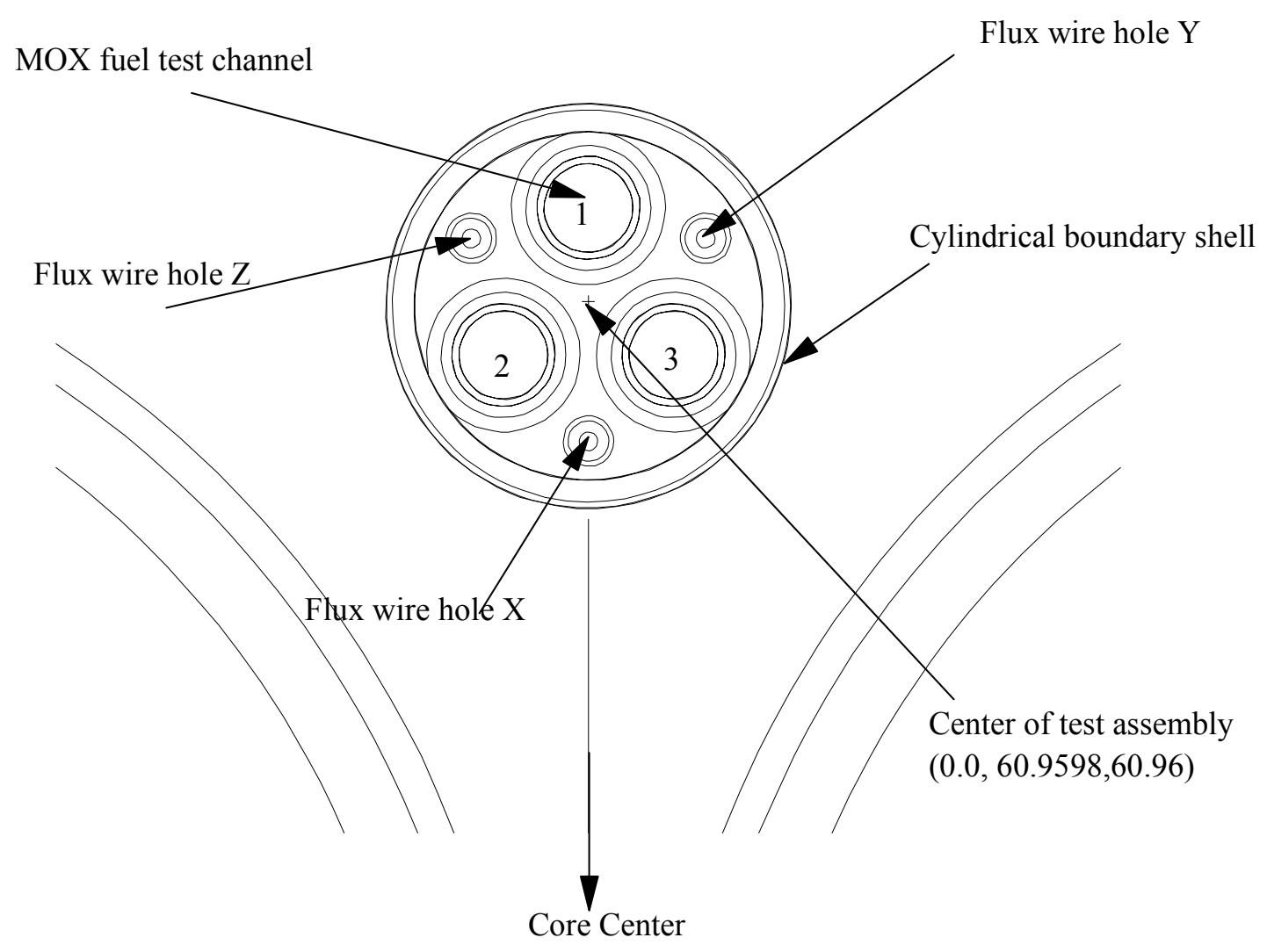

Figure 2. Detailed radial cross-sectional view of the WG-MOX fuel test assembly. 


\section{VALIDATION OF WG-MOX FUEL TEST ASSEMBLY MODEL}

The ability to accurately predict MOX fuel capsule power is essential to the WG-MOX fuel capsule design. The MCNP-calculated thermal and fast neutron fluxes were benchmarked against the measured Co-59 (thermal neutron flux) and Ni-58 (fast neutron flux) neutron monitor data.

The axial profile of the measured thermal and fast neutron fluxes along channel $\mathrm{Y}$ and the MCNP-calculated flux average positions are shown in Figure 3. Figure 3 shows that the thermal neutron flux is depressed along the MOX fuel pin, due to the high thermal Pu fission crosssection, while the fast neutron flux peaks at the center of MOX fuel pin. The averaged thermal neutron flux Calculated-to-Measured $(\mathrm{C} / \mathrm{M})$ ratios of channels $\mathrm{X}, \mathrm{Y}$, and $\mathrm{Z}$ are 1.05, 1.08, and 1.00 , respectively, as listed in Table 1. For this experiment, these $\mathrm{C} / \mathrm{M}$ ratios demonstrate excellent agreement. Some of the smaller regions do not agree as well due to the statistical nature of Monte Carlo and the flux-wire counting.

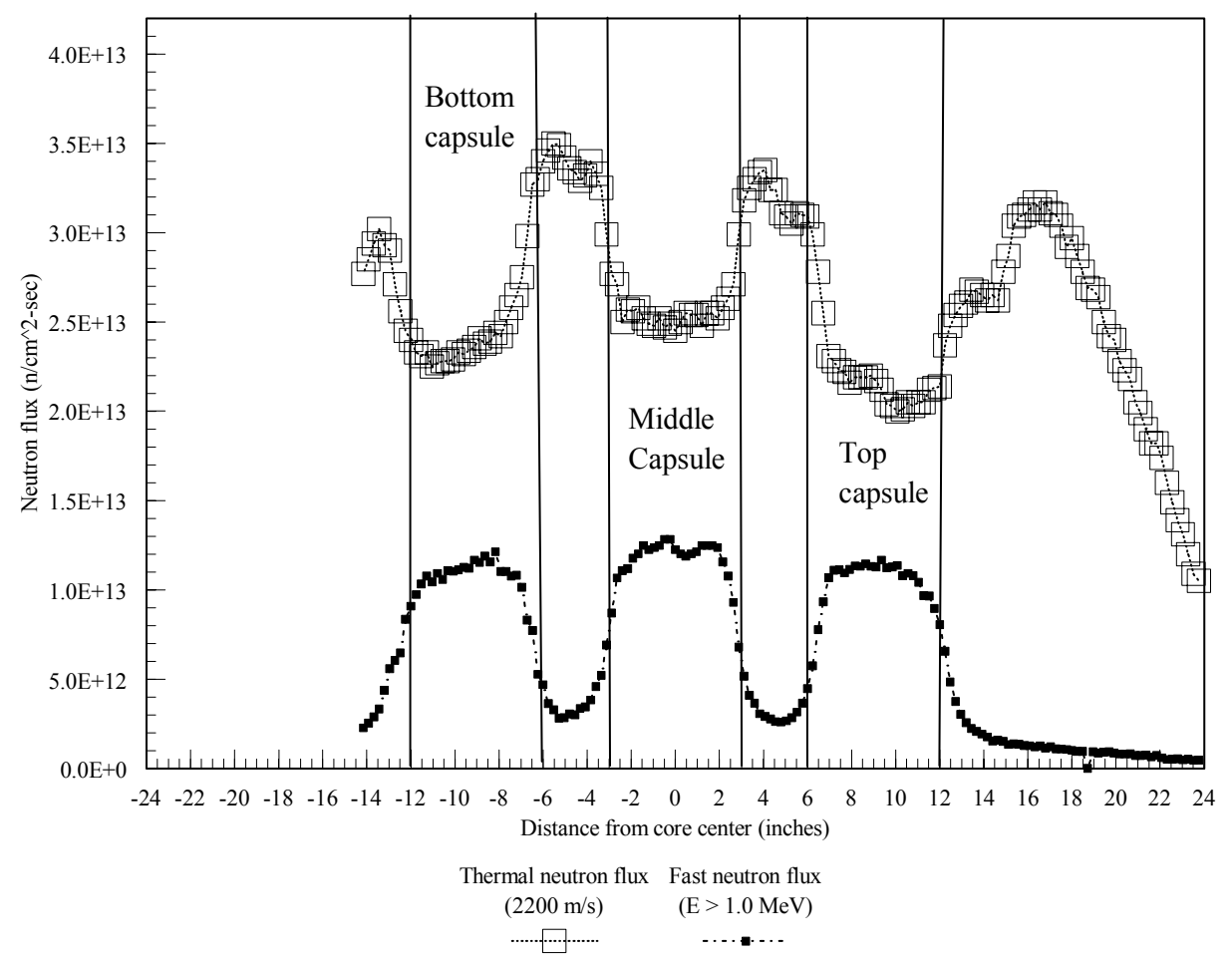

Figure 3. Measured channel Y thermal and fast neutron fluxes (ATR Cycle 115-C).

The ${ }^{58} \mathrm{Ni}(\mathrm{n}, \mathrm{p}){ }^{58} \mathrm{Co}$ effective cross-section and the empirical correction factor vary with respect to the specific reactor and monitor location. For ATR, the fission spectrum weighted over E $>1$ $\mathrm{MeV},{ }^{58} \mathrm{Ni}(\mathrm{n}, \mathrm{p}){ }^{58} \mathrm{Co}$ effective cross-section is $133 \mathrm{mb}$ for in-core locations, and the unperturbed ${ }^{58} \mathrm{Ni}(\mathrm{n}, \mathrm{p}){ }^{58} \mathrm{Co}$ effective cross-section at the I-24 experiment position is $97 \mathrm{mb} .{ }^{5}$ To account for the spectral perturbations caused by the MOX fuel pins in the in I-24 position, comparison calculations were performed to estimate the spectrum weighted ${ }^{58} \mathrm{Ni}(\mathrm{n}, \mathrm{p})^{58} \mathrm{Co}$ effective crosssection for 3 cases. 
Case 1 is the isolated MOX test assembly model having a spherical incoming neutron source with fission spectrum. Case 2 is with the MOX test fuel assembly in the ATR I-24 position. Case 3 has Aluminum fillers in the ATR I-24 position, simulating the unperturbed condition. The MCNP-calculated ${ }^{58} \mathrm{Ni}(\mathrm{n}, \mathrm{p}){ }^{58} \mathrm{Co}$ effective cross-section, which is a ratio of the reaction rate to the fast neutron flux, for cases 1,2 , and 3 are 151,120 , and $88 \mathrm{mb}$, respectively. If we assume that the MCNP-calculated ${ }^{58} \mathrm{Ni}(\mathrm{n}, \mathrm{p}){ }^{58} \mathrm{Co}$ cross-section is proportional to the ATR ${ }^{58} \mathrm{Ni}(\mathrm{n}, \mathrm{p}){ }^{58} \mathrm{Co}$ reaction rates, then the MOX perturbed spectral-averaged ${ }^{58} \mathrm{Ni}(\mathrm{n}, \mathrm{p})^{58} \mathrm{Co}$ cross-section is 114.1 $\mathrm{mb}$. Therefore, a scale factor of $133 / 114.1=1.17$, was applied to the measured fast neutron flux. The spectral-corrected fast neutron fluxes are summarized in Table 1. These spectral corrected fast neutron fluxes show good agreement with the MCNP-calculated fast neutron fluxes. Good agreement is also achieved for neutron monitor measurements from other ATR cycles. Note the estimated uncertainties in the thermal $(2200 \mathrm{~m} / \mathrm{s})$ and fast $(\mathrm{E}>1 \mathrm{MeV})$ neutron fluxes at the 68 percent confidence level are $\pm 3 \%$ and $\pm 5 \%$, respectively. The fast neutron flux uncertainty does not include the uncertainty in the spectrum averaged cross-section.

Table 1. Comparison of MCNP-Calculated and Measured Thermal and Fast Neutron Fluxes at Small I-24 Position (ATR Cycle 115-C).

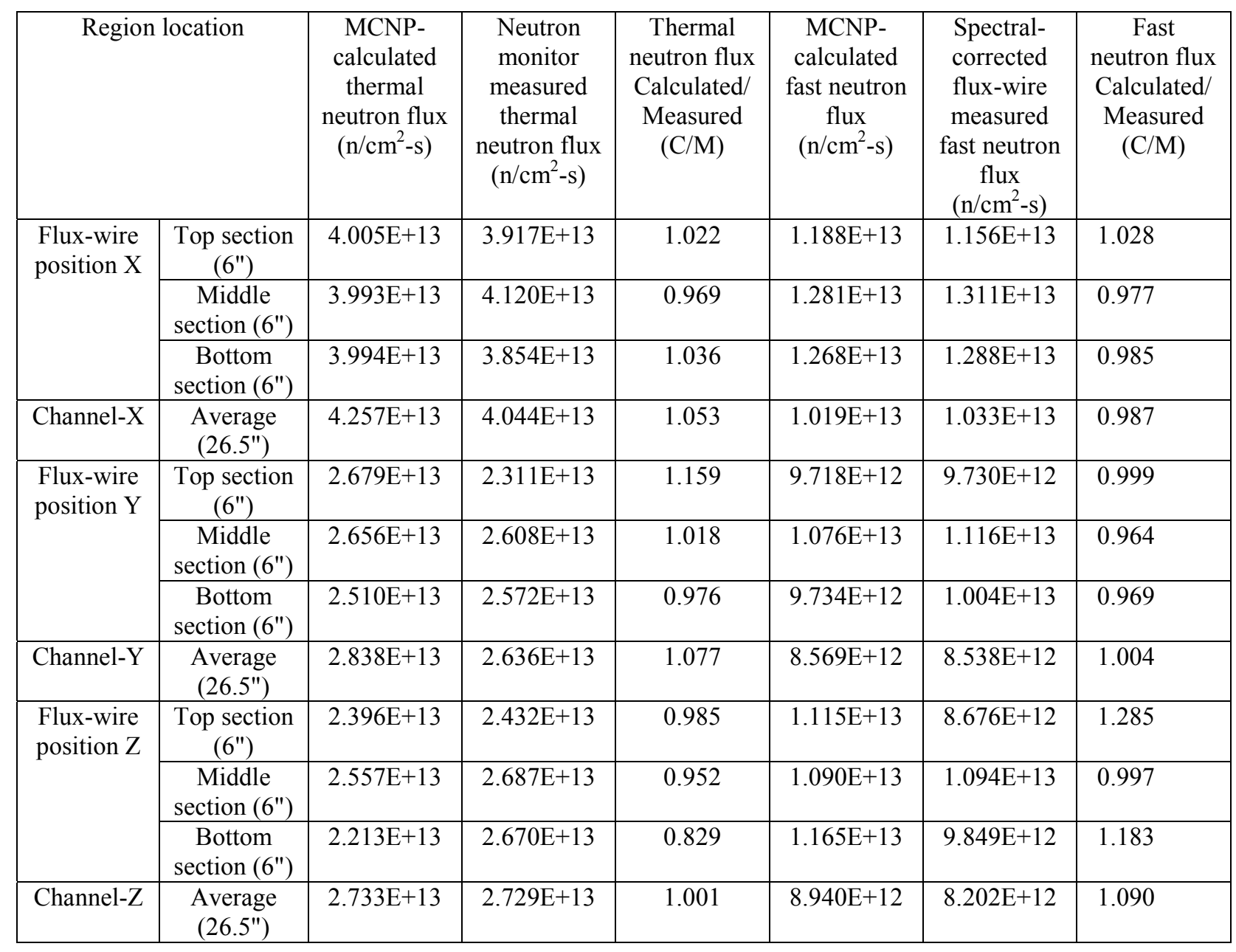




\section{RESULTS AND DISCUSSION}

The initial experiment phase (Phase-I irradiation), which contained nine MOX fuel capsules, was loaded into the ATR in January 1998. After 153.5 effective full power days (EFPDs) of irradiation in Phase-I, ${ }^{6}$ a capsule pair was withdrawn from the ATR in September 1998 after having achieved an average discharge burnup of about $8.6 \mathrm{GWd} / \mathrm{t}$.

At the end of Phase-II ${ }^{7}$ irradiation (226.9 EFPDs), an additional capsule pair was withdrawn in September 1999 after having achieved an average discharge burnup of about $21 \mathrm{GWd} / \mathrm{t}$. Also, at the end of Phase-III ${ }^{8}$ irradiation (232.8 EFPDs), an additional capsule pair was withdrawn in September 2000, after having achieved an average discharge burnup of about $29.6 \mathrm{GWd} / \mathrm{t}$. The Phase-IV Part- $1{ }^{9}$ MOX capsule arrangement ${ }^{10}$ was achieved by placing Capsules 6 and 12 in the two top positions of channels 2 and 3, Capsules 4 and 13 in the two middle positions of channels 2 and 3 , and Capsule 5 in the middle position of channel 1 . The other four assembly positions were filled with dummy stainless steel (SST) capsules.

To increase the linear heat generation rate (LHGR) during the Phase-IV Part-1, ${ }^{9}$ starting at Cycle 126B, the MOX fuel test assembly was moved to SW I-23 position. At the end of Phase-IV Part1 , the capsules 4 and 13 were removed for post irradiation examination (PIE).

The Phase-IV Part-2 MOX capsule arrangement was achieved by placing Capsules 6 and 12 in the two middle positions of channels 2 and 3, and Capsule 5 in the top position of channel 1 This report documents the MCWO-calculated fuel burnup from Cycle $115 \mathrm{C}$ to the end of Cycle 132C (50 GWd/t) during Phase-IV Part-2 MOX fuel irradiation. The ATR power history from the initial irradiation cycle to the final irradiation cycle (Cycle-115C through Cycle-132C) is summarized in Table 2 .

A typical cycle in the physics analysis is evenly divided into three intervals - beginning of cycle (BOC), middle of cycle (MOC), and end of cycle (EOC). Based on the data from the ATR SUrveillance DAta System (ASUDAS) and Core Safety Assurance Package (CSAP), the neckshim and outer shim control cylinder (OSCC) positions for each interval case run were updated. Then, using the BOC and the EOC fuel and B-10 from the CSAP data, the fuel and B-10 is linearly depleted from BOC to EOC. The fuel reaction tally in MCNP calculates the reaction rates in each cell, which is then normalized to quadrant power for the burnup calculation.

The experimental results of the Average Power Test (APT) include observations from the fuel fabrication process, PIE findings, $\mathrm{U}$ and Pu isotopic composition, and MOX fuel burnup. All of the capsules were visually examined in the transfer canal at the ATR during the shuffling and transfer to ORNL for PIE. All of the irradiated capsules appeared as fresh as they did at the original insertion. No changes in the external dimensions were noted. Oxidation of the external surfaces was likewise not noticeable. No appreciable scratches or wear spots were observed as might occur from fretting. MCWO was used to track fuel burnup and heat rates as functions of irradiation time. In summary, no anomalies were observed. 
Table 2. ATR power history from 1st irradiation Cycle-115C to final Cycle-132C.

\begin{tabular}{|c|c|c|c|c|c|c|c|c|}
\hline Cycles ID & NW (MW) & NE & $\mathrm{C}$ & SW & SE & Core power MW & MWd & EFPD \\
\hline $115 \mathrm{C}-1$ & 17.0 & 18.0 & 23.0 & 23.0 & 23.0 & 104.0 & 5033.6 & 48.4 \\
\hline $116 \mathrm{~A}-1$ & 17.0 & 18.0 & 29.7 & 34.0 & 43.2 & 141.9 & 1816.3 & 12.8 \\
\hline 116B-1 & 17.0 & 18.0 & 23.4 & 23.0 & 25.0 & 106.4 & 2362.1 & 22.2 \\
\hline $117 \mathrm{~A}-1$ & 19.0 & 19.0 & 39.8 & 45.4 & 47.3 & 170.5 & 2404.1 & 14.1 \\
\hline 117B-1 & 17.0 & 18.8 & 24.3 & 22.0 & 25.5 & 107.6 & 6176.2 & 57.4 \\
\hline $118 \mathrm{~A}-1$ & 17.0 & 18.0 & 24.3 & 22.0 & 27.0 & 108.3 & 5241.7 & 48.4 \\
\hline 118B-1 & 17.0 & 18.0 & 24.4 & 22.0 & 27.0 & 108.4 & 3945.8 & 36.4 \\
\hline 119A-1 & 13.3 & 18.0 & 22.1 & 23.0 & 24.0 & 100.4 & 1927.7 & 19.2 \\
\hline 119A-2 & 17.0 & 18.1 & 23.2 & 23.0 & 23.8 & 105.1 & 262.8 & 2.5 \\
\hline 119A-3 & 15.4 & 18.0 & 23.2 & 23.0 & 24.0 & 103.6 & 4620.6 & 44.6 \\
\hline 119B-1 & 17.0 & 16.6 & 23.1 & 23.0 & 27.0 & 106.7 & 4492.1 & 42.1 \\
\hline $120 \mathrm{~A}-1$ & 17.0 & 17.5 & 22.0 & 22.0 & 24.0 & 102.5 & 5760.5 & 56.2 \\
\hline 120B-1 & 21.0 & 18.2 & 34.9 & 44.7 & 45.7 & 164.5 & 329.0 & 2.0 \\
\hline 120B-2 & 17.0 & 18.3 & 32.6 & 38.6 & 44.2 & 150.7 & 512.4 & 3.4 \\
\hline $120 \mathrm{C}-1$ & 16.5 & 18.0 & 24.5 & 23.0 & 26.9 & 108.9 & 3702.6 & 34.0 \\
\hline $121 \mathrm{~A}-1$ & 15.9 & 18.0 & 34.4 & 44.8 & 36.0 & 149.1 & 2087.4 & 14.0 \\
\hline 121B-1 & 16.2 & 17.7 & 25.3 & 23.0 & 30.0 & 112.2 & 5194.9 & 46.3 \\
\hline $121 \mathrm{C}-1$ & 16.2 & 18.0 & 23.3 & 23.0 & 23.0 & 103.5 & 4895.6 & 47.3 \\
\hline $122 \mathrm{~A}-1$ & 17.0 & 18.0 & 26.7 & 23.0 & 32.0 & 116.7 & 4773.0 & 40.9 \\
\hline 122B-1 & 17.0 & 18.1 & 29.3 & 34.5 & 35.2 & 134.1 & 160.9 & 1.2 \\
\hline $122 \mathrm{C}-1$ & 17.0 & 18.6 & 23.3 & 23.0 & 23.0 & 104.9 & 5234.5 & 49.9 \\
\hline $123 \mathrm{~A}-1$ & 17.7 & 19.0 & 39.3 & 52.8 & 45.0 & 173.8 & 2224.6 & 12.8 \\
\hline 123B-1 & 17.0 & 17.9 & 24.1 & 23.0 & 27.0 & 109.0 & 4599.8 & 42.2 \\
\hline $123 \mathrm{C}-1$ & 17.0 & 18.0 & 28.2 & 32.3 & 33.0 & 128.5 & 1721.9 & 13.4 \\
\hline $124 \mathrm{~A}-1$ & 17.0 & 18.0 & 25.3 & 23.0 & 27.0 & 110.3 & 6342.3 & 57.5 \\
\hline 124B-1 & 18.0 & 16.6 & 32.5 & 47.4 & 44.1 & 158.6 & 111.0 & 0.7 \\
\hline $124 \mathrm{C}-1$ & 17.0 & 18.5 & 24.6 & 23.0 & 27.0 & 110.1 & 4415.0 & 40.1 \\
\hline $125 \mathrm{~A}-1$ & 18.0 & 16.0 & 25.1 & 23.0 & 25.0 & 107.1 & 3416.5 & 31.9 \\
\hline $125 \mathrm{~A}-2$ & 17.9 & 15.9 & 25.7 & 22.9 & 24.9 & 107.3 & 5794.2 & 54.0 \\
\hline $125 \mathrm{~B}-1$ & 17.0 & 16.0 & 23.9 & 25.1 & 25.0 & 107.0 & 5339.3 & 49.9 \\
\hline 126A-1 & 17.1 & 16.0 & 23.2 & 23.0 & 25.1 & 104.4 & 4144.7 & 39.7 \\
\hline 126B-1 & 18.0 & 16.0 & 23.7 & 23.0 & 25.0 & 105.7 & 5221.6 & 49.4 \\
\hline 127A-1 & 18.1 & 16.0 & 23.5 & 23.1 & 25.1 & 105.8 & 5924.8 & 56.0 \\
\hline 127B-1 & 17.8 & 16.0 & 32.0 & 46.3 & 49.9 & 162.0 & 81.0 & 0.5 \\
\hline $127 \mathrm{C}-1$ & 18.0 & 16.0 & 23.3 & 25.0 & 25.0 & 107.3 & 5397.2 & 50.3 \\
\hline $128 \mathrm{~A}-1$ & 17.9 & 18.0 & 22.6 & 24.1 & 24.6 & 107.2 & 6421.3 & 59.9 \\
\hline 128B-1 & 18.0 & 18.0 & 29.7 & 38.0 & 33.6 & 137.3 & 1990.9 & 14.5 \\
\hline 129A-1 & 18.0 & 18.0 & 22.7 & 25.0 & 25.0 & 108.7 & 5619.8 & 51.7 \\
\hline 129B-1 & 18.0 & 18.0 & 24.1 & 25.0 & 23.0 & 108.1 & 4734.8 & 43.8 \\
\hline $130 \mathrm{~A}-1$ & 18.0 & 18.0 & 24.1 & 23.0 & 25.0 & 108.1 & 5567.2 & 51.5 \\
\hline 130B-1 & 18.0 & 17.0 & 24.2 & 23.0 & 25.0 & 107.2 & 4770.4 & 44.5 \\
\hline $131 \mathrm{~A}-1$ & 18.0 & 17.0 & 24.3 & 23.0 & 24.6 & 106.9 & 5184.7 & 48.5 \\
\hline 131B-1 & 18.3 & 18.0 & 34.2 & 37.3 & 44.3 & 152.1 & 2099.0 & 13.8 \\
\hline
\end{tabular}




\begin{tabular}{|c|c|c|c|c|c|c|c|c|}
\hline 132A-1 & 18.0 & 18.0 & 25.7 & 23.0 & 27.0 & 111.7 & 2613.8 & 23.4 \\
\hline $132 \mathrm{~A}-2$ & 18.0 & 18.0 & 25.6 & 23.0 & 27.0 & 111.6 & 4921.6 & 44.1 \\
\hline 132B-1 & 18.0 & 18.0 & 33.9 & 43.8 & 45.4 & 159.1 & 254.6 & 1.6 \\
\hline $132 \mathrm{C}-1$ & 18.0 & 18.0 & 25.6 & 23.0 & 27.0 & 111.6 & 5613.5 & 50.3 \\
\hline
\end{tabular}

\subsection{MCWO-calculated Burnup during Phase-I Irradiation}

Using the detailed ATR quarter core model provide the calculated neutronics tallies, the MCWOcalculated Phase-I burnup distribution for the end of each irradiation cycle was tabulated and is shown in Table 3. At the end of Phase-I irradiations, the LHGR-estimated burnup for MOX fuel capsules 1 and 8 was 8.63 and $8.54 \mathrm{GWd} / \mathrm{t}$, respectively. At the end of Phase-I irradiations, MOX fuel capsules 1 and 8 were removed and shipped to ORNL for PIE.

Table 3. MCWO-calculated burnup of the Phase-I MOX fuel capsules in the I-24 position of ATR from Cycle 115C to Cycle 117B (at the end of each irradiation Cycle).

\begin{tabular}{|c|c|c|c|c|c|c|c|}
\hline \multicolumn{2}{|c|}{ Target location } & \multirow{4}{*}{$\begin{array}{c}\text { Capsule } \\
\text { ID }^{\mathrm{a}}\end{array}$} & Cycle & Cycle & Cycle & Cycle & Cycle \\
\hline & & & 115 & $116 \mathrm{~A}$ & $116 \mathrm{~B}$ & $11 / \mathrm{A}$ & $117 \mathrm{~B}$ \\
\hline & & & EFPDs & EFPDs & EFPDs & EFPDs & EFPDs \\
\hline & & & \multicolumn{5}{|c|}{$\mathrm{GWd} / \mathrm{t}$} \\
\hline \multirow[t]{3}{*}{ Top } & Back 1 & 4 & 2.00 & 2.47 & 3.38 & 3.91 & 6.13 \\
\hline & Left 2 & 10 & 2.77 & 3.44 & 4.69 & 5.40 & 8.35 \\
\hline & Right 3 & 3 & 2.79 & 3.45 & 4.70 & 5.41 & 8.36 \\
\hline \multirow[t]{3}{*}{ Middle } & Back 4 & 5 & 2.09 & 2.60 & 3.55 & 4.11 & 6.37 \\
\hline & Left 5 & 1 & 2.90 & 3.59 & 4.88 & 5.62 & 8.63 \\
\hline & Right 6 & 8 & 2.87 & 3.55 & 4.83 & 5.55 & 8.54 \\
\hline \multirow[t]{3}{*}{ Bottom } & Back 7 & 13 & 2.02 & 2.50 & 3.42 & 3.95 & 6.11 \\
\hline & Left 8 & 9 & 2.79 & 3.47 & 4.71 & 5.43 & 8.37 \\
\hline & Right 9 & 2 & 2.77 & 3.43 & 4.69 & 5.40 & 8.30 \\
\hline
\end{tabular}

Notes:

The as-run Cycles from 115C to 117B core loadings were selected to generate the MOX fuel neutron cross sections and LHGR for burnup calculations.

All table values have a relative uncertainty band $(1 \sigma)=2.5 \%$.

a. $\quad$ Capsule ID numbers are from Figure 2 in Reference 9.

\subsection{MCWO-calculated Burnup during Phase-II Irradiation}

The MCWO-calculated Phase-II burnup distribution for the end of each irradiation cycle is summarized in Table 4. For the end of Phase-II irradiations, the MCWO-calculated burnup for MOX fuel capsules 9 and 2 was 20.95 and $20.90 \mathrm{GWd} / \mathrm{t}$, respectively. At the end of Phase-II irradiations, MOX fuel capsules 9 and 2 were removed and shipped to ORNL for the PIE. 
Table 4. MCWO-calculated burnup of the Phase-II MOX fuel capsules in the I-24 position of ATR from Cycle 118A to Cycle 120A (at the end of each irradiation Cycle).

\begin{tabular}{|c|c|c|c|c|c|c|c|}
\hline \multicolumn{2}{|c|}{ Target location } & \multirow{4}{*}{$\begin{array}{c}\text { Capsule } \\
\text { ID }^{\mathrm{a}}\end{array}$} & Cycle & Cycle & Cycle & Cycle & Cycle \\
\hline & & & $118 \mathrm{~A}$ & $118 \mathrm{~B}$ & $119 \mathrm{~A}$ & 119B & $120 \mathrm{~A}$ \\
\hline & & & EFPDs & EFPDs & EFPDs & EFPDs & EFPDs \\
\hline & & & \multicolumn{5}{|c|}{$\mathrm{GWd} / \mathrm{t}$} \\
\hline \multirow[t]{3}{*}{ Top } & Back 1 & 6 & 2.81 & 4.88 & 6.93 & 9.03 & 11.70 \\
\hline & Left 2 & 10 & 11.53 & 13.82 & 16.00 & 18.22 & 20.97 \\
\hline & Right 3 & 3 & 11.55 & 13.84 & 16.01 & 18.25 & 21.02 \\
\hline \multirow{3}{*}{ Middle } & Back 4 & 5 & 8.97 & 10.87 & 12.78 & 14.75 & 17.22 \\
\hline & Left 5 & 4 & 9.59 & 12.06 & 14.44 & 16.93 & 19.96 \\
\hline & Right 6 & 13 & 9.58 & 12.09 & 14.50 & 16.97 & 19.99 \\
\hline \multirow[t]{3}{*}{ Bottom } & Back 7 & 12 & 2.80 & 4.86 & 6.90 & 9.04 & 11.73 \\
\hline & Left 8 & 9 & 11.50 & 13.75 & 15.91 & 18.18 & 20.95 \\
\hline & Right 9 & 2 & 11.38 & 13.65 & 15.82 & 18.11 & 20.90 \\
\hline
\end{tabular}

Notes

All table values have a relative uncertainty band $(1 \sigma)=2.5 \%$.

a. $\quad$ Capsule ID numbers are from Fig. 2 in Ref. 9.

\subsection{MCWO-calculated Burnup during Phase-III (Part-1) Irradiation}

The MCWO-calculated Phase-III burnup distribution for the end of each irradiation cycle is summarized in Table 5. At the end of Phase-III irradiations, the LHGR-estimated burnup for MOX fuel capsules 10 and 3 was 29.61 and $29.66 \mathrm{GWd} / \mathrm{t}$, respectively. At the end of Phase-III irradiations, the MOX fuel capsules 10 and 3 were removed and shipped to ORNL for PIE.

Table 5. MCWO-calculated burnup of the phase-III MOX fuel capsules in the I-24 position of ATR from Cycle 120C to Cycle 122C.

\begin{tabular}{|c|c|c|c|c|c|c|}
\hline \multicolumn{2}{|c|}{ Target location } & $\begin{array}{c}\text { Capsule } \\
\text { ID }^{\mathrm{a}}\end{array}$ & $\begin{array}{c}\text { Cycle 120C } \\
34.0 \text { EFPDs } \\
(\mathrm{GWd} / \mathrm{t})\end{array}$ & $\begin{array}{c}\text { Cycle 121A } \\
\text { 14 EFPDs }\end{array}$ & $\begin{array}{c}\text { Cycle 121B-2 } \\
\text { 46.3 EFPDs }\end{array}$ & $\begin{array}{c}\text { Cycle 121C } \\
\text { 47.3 EFPDs }\end{array}$ \\
\hline \multirow{3}{*}{ Top } & Back 1 & 6 & 13.19 & 13.67 & 15.51 & 17.33 \\
\cline { 2 - 7 } & Left 2 & 10 & 22.44 & 22.91 & 24.68 & 26.42 \\
\cline { 2 - 7 } & Right 3 & 3 & 22.50 & 22.96 & 24.73 & 26.47 \\
\hline \multirow{3}{*}{ Middle } & Back 4 & 5 & 18.66 & 19.14 & 20.88 & 22.59 \\
\cline { 2 - 7 } & Left 5 & $*$ SST & 0.00 & 0.00 & 0.00 & 0.00 \\
\cline { 2 - 7 } & Right 6 & $*$ SST & 0.00 & 0.00 & 0.00 & 0.00 \\
\hline \multirow{3}{*}{ Bottom } & Back 7 & 12 & 13.23 & 13.72 & 15.54 & 17.36 \\
\cline { 2 - 7 } & Left 8 & 4 & 21.48 & 21.96 & 23.79 & 25.57 \\
\cline { 2 - 7 } & Right 9 & 13 & 21.50 & 22.00 & 23.83 & 25.62 \\
\hline
\end{tabular}

Notes:

All table values have a relative uncertainty band $(1 \sigma)=2.5 \%$.

a. $\quad$ Capsule ID numbers are from Fig. 4 in Ref. 9. 
Table 5. MCWO-calculated burnup of the phase-III MOX fuel capsules in the I-24 position of ATR from Cycle 120C to Cycle 122C (continued).

\begin{tabular}{|c|c|c|c|c|}
\hline \multicolumn{2}{|c|}{ Target location } & \multirow{2}{*}{$\begin{array}{c}\text { Capsule } \\
\text { ID }^{\mathrm{a}}\end{array}$} & Cycle & Cycle \\
\hline & & & \multicolumn{2}{|c|}{$\overline{\mathrm{GWd} / \mathrm{t}}$} \\
\hline \multirow[t]{3}{*}{ Top } & Back 1 & 6 & 18.87 & 20.78 \\
\hline & Left 2 & 10 & 27.86 & 29.61 \\
\hline & Right 3 & 3 & 27.91 & 29.66 \\
\hline \multirow[t]{3}{*}{ Middle } & Back 4 & 5 & 24.00 & 25.77 \\
\hline & Left 5 & * SST & 0.00 & 0.00 \\
\hline & Right 6 & * SST & 0.00 & 0.00 \\
\hline \multirow[t]{3}{*}{ Bottom } & Back 7 & 12 & 18.91 & 20.83 \\
\hline & Left 8 & 4 & 27.04 & 28.86 \\
\hline & Right 9 & 13 & 27.08 & 28.90 \\
\hline
\end{tabular}

Notes:

All table values have a relative uncertainty band $(1 \sigma)=2.5 \%$.

a. $\quad$ Capsule ID numbers are from Fig. 4 in Ref. 9.

\subsection{MCWO-calculated Burnup during Phase-III (Part-2) Irradiation}

The loading pattern for the Phase III, Part-2 Equalization of Burnup was suggested by the project managers and is now included in Reference 10. Upon completion of the Phase-III irradiations (the end of Cycle 122C), five capsules were kept at INL for participation in Phase IV. Their respective predicted burnups were:

Capsule 4 - $28.9 \mathrm{GWd} / \mathrm{t}$

Capsule 5 - $26.0 \mathrm{GWd} / \mathrm{t}$

Capsule 6 - $21.0 \mathrm{GWd} / \mathrm{t}$
Capsule 13 - $28.9 \mathrm{GWd} / \mathrm{t}$

Capsule 12 - $20.9 \mathrm{GWd} / \mathrm{t}$.

Project management decided to consider irradiation of capsules 5, 6, and 12 alone in a four cycle extension of Phase III. The purpose would be to more nearly equalize capsule burnup before proceeding beyond $30 \mathrm{GWd} / \mathrm{MT}$, and could be best accomplished by placing capsules 6 and 12 in the two middle positions of channels 2 and 3 with capsule 5 in the middle position of channel 1, as shown in Figure 5, Reference 10. The other six assembly positions were be filled with dummy SST capsules. For the end of the Phase-III, Part-2 irradiations, the MCNP-calculated burnup, using the updated detailed quarter ATR core model with an 80-mil Al shroud, are summarized in Table 6. The burnup of capsules ID 5, 6, and 12 reached 29.55, 26.28, and 26.31 $\mathrm{GWd} / \mathrm{t}$, respectively. 
Table 6. Burnup of the Phase-III, Part-2 MOX fuel capsules in the I-24 position of ATR from Cycle 122C through Cycle 124A.

\begin{tabular}{|c|c|c|c|c|c|c|}
\hline \multicolumn{2}{|c|}{ Target location } & Capsule ID & \begin{tabular}{c} 
Cycle 123A \\
14 EFPDs \\
\multicolumn{2}{|c|}{}
\end{tabular} & $\begin{array}{c}\text { Cycle 123B } \\
\text { 44 EFPDs } \\
(10 / 01 / 00)\end{array}$ & $\begin{array}{c}\text { Cycle 123C } \\
\text { 14 EFPDs } \\
(11 / 05 / 00)\end{array}$ & $\begin{array}{c}\text { Cycle 124A } \\
58 \text { EFPDs } \\
(01 / 07 / 01)\end{array}$ \\
\cline { 3 - 7 } & & \multicolumn{4}{|c|}{ GWd/t } \\
\hline \multirow{3}{*}{ Top } & Back 1 & SST & 0.00 & 0.00 & 0.00 & 0.00 \\
\cline { 2 - 7 } & Left 2 & SST & 0.00 & 0.00 & 0.00 & 0.00 \\
\cline { 2 - 7 } & Right 3 & SST & 0.00 & 0.00 & 0.00 & 0.00 \\
\hline \multirow{3}{*}{ Middle } & Back 4 & 5 & 26.23 & 27.54 & 27.94 & 29.55 \\
\cline { 2 - 7 } & Left 5 & 6 & 21.37 & 23.32 & 23.91 & 26.28 \\
\cline { 2 - 7 } & Right 6 & 12 & 21.24 & 23.27 & 23.88 & 26.31 \\
\hline \multirow{3}{*}{ Bottom } & Back 7 & SST & 0.00 & 0.00 & 0.00 & 0.00 \\
\cline { 2 - 7 } & Left 8 & SST & 0.00 & 0.00 & 0.00 & 0.00 \\
\cline { 2 - 7 } & Right 9 & SST & 0.00 & 0.00 & 0.00 & 0.00 \\
\hline
\end{tabular}

Notes:

Capsules 4 and 13, with a projected burnup of $28.9 \mathrm{GWd} / \mathrm{t}$ will be stored in the ATR canal in the MOX carrier, during these irradiation cycles.

All table values have a relative uncertainty band $(1 \sigma)=2.5 \%$.

a. $\quad$ Capsule ID numbers are from Fig. 5 in Ref. 9.

\subsection{MCWO-calculated Burnup during Phase-IV (Part-1) Irradiation}

With the two lead burnup capsules removed for PIE at the end of Phase-III MOX fuel irradiation (30 GWd/MT), five capsules were eligible for additional irradiation during Phase-IV irradiation. The purpose of Phase-IV would be to carry MOX capsule burnup beyond $30 \mathrm{GWd} / \mathrm{t}$ and up to 50 $\mathrm{GWd} / \mathrm{t}$. The main challenge when extending the burnup of the five average-power test capsules beyond $30 \mathrm{GWd} / \mathrm{t}$ is the small initial diametrical gap (2.0 to $3.5 \mathrm{mils})$ between pellets and clad.

The Phase-IV Part 1 MOX capsule arrangement ${ }^{10}$ placed capsules 6 and 12 in the two top positions of channels 2 and 3, capsules 4 and 13 in the two middle positions of channels 2 and 3 , and capsule 5 in the middle position of channel 1. The other four assembly positions are filled with dummy SST capsules. Calculations use the detailed quarter ATR core model with an 80mil Al shroud.

The MCNP-calculated burnup for the end of each irradiation cycles from 124C to 126A are summarized in Table 7 for the Phase-IV, Part-1A. At the end of Cycle 126A, the lead burnup MOX fuel capsule reached $34.89 \mathrm{GWd} / \mathrm{t}$.

To increase the LHGR and speed up MOX fuel burnup rate, starting from Cycle 126B (PhaseIV, Part-1), the MOX test assembly was moved to the SW small I-23 position, with SW lobe power of $23 \mathrm{MW}$ (SW quadrant power of 29.1 MW). Concern for the MOX fuel capsule integrity, the MOX fuel test assembly sat out the high power PALM cycle (Cycle 127B). The MCNP and ORIGEN-2 calculated burnup and LHGR distributions are summarized in Table 8. The lead capsule's burnup at the end of Phase-IV (at the end of Cycle 127C), Part-1 reached $39.859 \mathrm{GWd} / \mathrm{t}$. 
Table 7. Burnup (GWd/t) of the Phase-IV, Part-1 MOX fuel capsules in the NW I-24 position of ATR at the end of irradiation Cycle s from 124C to 126A.

\begin{tabular}{|c|c|c|c|c|c|c|}
\hline \multicolumn{2}{|c|}{ Target location } & \multirow{2}{*}{ ID } & $124 \mathrm{C}$ & $125 \mathrm{~A}$ & $125 \mathrm{~B}$ & $126 \mathrm{~A}$ \\
\cline { 3 - 7 } \multicolumn{2}{|c|}{} & $\begin{array}{c}40.1 \\
\text { EFPDs }\end{array}$ & $\begin{array}{c}54.0 \\
\text { EFPDs }\end{array}$ & $\begin{array}{c}49.9 \\
\text { EFPDs }\end{array}$ & $\begin{array}{c}39.7 \\
\text { EFPDs }\end{array}$ \\
\hline \multirow{3}{*}{ Top } & Back 1 & SST & 0.00 & 0.00 & 0.00 & 0.00 \\
\cline { 2 - 7 } & Left 2 & 6 & 27.43 & 29.09 & 30.94 & 32.37 \\
\cline { 2 - 7 } & Right 3 & 12 & 27.53 & 29.22 & 31.07 & 32.51 \\
\hline Middle & Back 4 & 5 & 30.24 & 31.45 & 32.80 & 33.88 \\
\cline { 2 - 7 } & Left 5 & 4 & 30.31 & 31.86 & 33.56 & 34.89 \\
\cline { 2 - 7 } & Right 6 & 13 & 30.36 & 31.91 & 33.59 & 34.90 \\
\hline Bottom & Back 7 & SST & 0.00 & 0.00 & 0.00 & 0.00 \\
\cline { 2 - 7 } & Left 8 & SST & 0.00 & 0.00 & 0.00 & 0.00 \\
\cline { 2 - 7 } & Right 9 & SST & 0.00 & 0.00 & 0.00 & 0.00 \\
\hline
\end{tabular}

Table 8. Burnup (GWd/t) of the Phase-IV, Part-1 MOX fuel capsules in the SW I-23 position (except high PALM Cycle 127B) of ATR at the end of irradiation Cycle s from 127A to 127C.

\begin{tabular}{|c|c|c|c|c|c|c|}
\hline \multicolumn{2}{|c|}{ Target location } & ID & $126 \mathrm{~B}$ & $127 \mathrm{~A}$ & $127 \mathrm{~B}$ & $127 \mathrm{C}$ \\
\cline { 3 - 7 } \multicolumn{2}{|c|}{} & & $\begin{array}{c}49.4 \\
\text { EFPDs }\end{array}$ & $\begin{array}{c}56.0 \\
\text { EFPDs }\end{array}$ & $\begin{array}{c}0.5 \\
\text { EFPDs }\end{array}$ & $\begin{array}{c}50.3 \\
\text { EFPDs }\end{array}$ \\
\hline \multirow{3}{*}{ Top } & Back 1 & SST & 0.00 & 0.00 & Sit out & 0.00 \\
\cline { 2 - 7 } & Left 2 & 6 & 33.79 & 36.00 & & 37.56 \\
\cline { 2 - 7 } & Right 3 & 12 & 33.94 & 36.17 & & 37.75 \\
\hline Middle & Back 4 & 5 & 34.96 & 36.68 & & 37.91 \\
\cline { 2 - 7 } & Left 5 & 4 & 36.21 & 38.34 & & 39.85 \\
\cline { 2 - 7 } & Right 6 & 13 & 36.21 & 38.33 & & 39.83 \\
\hline Bottom & Back 7 & SST & 0.00 & 0.00 & & 0.00 \\
\cline { 2 - 7 } & Left 8 & SST & 0.00 & 0.00 & & 0.00 \\
\cline { 2 - 7 } & Right 9 & SST & 0.00 & 0.00 & & 0.00 \\
\hline
\end{tabular}

\subsection{MCWO-calculated Burnup during Phase-IV (Part-2 and -3) Irradiation}

Project management decided to irradiate capsules 5, 6, and 12 alone in Phase-IV, Part-2. The Phase-IV, Part-2 MOX capsule arrangement ${ }^{10}$ placed capsules 6 and 12 in the two middle positions of channels 2 and 3 with capsule 5 in the top front position. The other six assembly positions were filled with dummy capsules. The purpose of Phase-IV Part-2 and Part-3 is to carry MOX capsule burnup beyond $40 \mathrm{GWd} / \mathrm{t}$ and up to $50 \mathrm{GWd} / \mathrm{t}$. In the MOX Phase-IV, Part3 , the remaining three MOX capsules (ID 6, 12, and 5) arrangement is the same as at the end of Phase -IV Part-2 (at the end of cycle 128A). The other six assembly positions were filled with dummy SST capsules. At the end of cycle 129B, the burnup of capsules (ID 6, 12, and 5) reached 43.71, 43.86, and $43.98 \mathrm{GWd} / \mathrm{t}$, respectively. 
The burnup at the end of Cycle 129B for capsules 5, 6, and 12 reached 43.44, 43.69, and 43.91 $\mathrm{GWd} / \mathrm{t}$, respectively, as given in Table 9. After Cycle 129B, Phase-IV Part-3, MCNPcalculations were performed to carry the MOX capsule burnup up to $50 \mathrm{GWd} / \mathrm{t}$ with the EFPDs of cycles 130A, 130B, 131A, 132A, and 132C as shown in Table 10. In this final Phase of irradiation, capsules 6 and 12 were placed in the two front middle positions and capsule 5 in the front top position. At the end of irradiation cycle, Cycle 132C, the burnup of capsules 6 and 12 reached 50.41 and $50.48 \mathrm{GWd} / \mathrm{t}$, respectively.

Table 9. Burnup (GWd/t) of the Phase-IV, Part-2 MOX fuel capsules in the SW I-23 position of ATR at the end of irradiation Cycles from 127C to 129B.

\begin{tabular}{|c|c|c|c|c|c|c|}
\hline \multicolumn{2}{|c|}{ Target location } & ID & $127 \mathrm{C}$ & $128 \mathrm{~A}$ & $129 \mathrm{~A}$ & $129 \mathrm{~B}$ \\
\cline { 3 - 7 } \multicolumn{2}{c|}{} & & $\begin{array}{c}50.3 \\
\text { EFPDs }\end{array}$ & $\begin{array}{c}59.9 \\
\text { EFPDs }\end{array}$ & $\begin{array}{c}51.7 \\
\text { EFPDs }\end{array}$ & $\begin{array}{c}43.8 \\
\text { EFPDs }\end{array}$ \\
\hline \multirow{3}{*}{ Top } & Back 1 & SST & 0.00 & 0.00 & 0.00 & 0.00 \\
\cline { 2 - 7 } & Left 2 & 5 & 0.00 & 0.00 & 0.00 & 0.00 \\
\cline { 2 - 7 } & Right 3 & SST & 38.68 & 40.57 & 42.07 & 43.44 \\
\hline \multirow{3}{*}{ Middle } & Back 4 & SST & 0.00 & 0.00 & 0.00 & 0.00 \\
\cline { 2 - 7 } & Left 5 & 6 & 38.41 & 40.52 & 42.18 & 43.69 \\
\cline { 2 - 7 } & Right 6 & 12 & 38.53 & 40.68 & 42.38 & 43.91 \\
\hline \multirow{3}{*}{ Bottom } & Back 7 & SST & 0.00 & 0.00 & 0.00 & 0.00 \\
\cline { 2 - 7 } & Left 8 & SST & 0.00 & 0.00 & 0.00 & 0.00 \\
\cline { 2 - 7 } & Right 9 & SST & 0.00 & 0.00 & 0.00 & 0.00 \\
\hline
\end{tabular}

Table 10. MCWO-calculated burnup of Phase-4 Part-3 MOX fuel capsules in the I-23 position of ATR from Cycle 130A to Cycle 132C.

\begin{tabular}{|c|c|c|c|c|c|c|c|}
\hline \multicolumn{2}{|c|}{ Target location } & $\begin{array}{c}\text { Capsule } \\
\text { ID }^{\mathrm{a}}\end{array}$ & $\begin{array}{c}\text { Cycle 130A } \\
51.5 \text { EFPDs }\end{array}$ & $\begin{array}{c}\text { Cycle 130B } \\
48.5 \text { EFPDs }\end{array}$ & $\begin{array}{c}\text { Cycle 131A } \\
56.0 \text { EFPDs }\end{array}$ & $\begin{array}{c}\text { Cycle 132A } \\
44.0 \text { EFPDs }\end{array}$ & $\begin{array}{c}\text { Cycle 132C } \\
50.3 \text { EFPDs }\end{array}$ \\
\cline { 3 - 8 } & & \multicolumn{5}{|c|}{} \\
\hline \multirow{3}{*}{ Top } & Back 1 & SST & 0.00 & 0.00 & 0.00 & 0.00 & 0.00 \\
\cline { 2 - 8 } & Left 2 & 5 & 45.07 & 46.33 & 47.72 & 48.77 & 49.79 \\
\cline { 2 - 8 } & Right 3 & SST & 0.00 & 0.00 & 0.00 & 0.00 & 0.00 \\
\hline \multirow{3}{*}{ Middle } & Back 4 & SST & 0.00 & 0.00 & 0.00 & 0.00 & 0.00 \\
\cline { 2 - 8 } & Left 5 & 6 & 45.33 & 46.68 & 48.17 & 49.31 & 50.41 \\
\cline { 2 - 8 } & Right 6 & 12 & 45.44 & 46.79 & 48.26 & 49.39 & 50.48 \\
\hline \multirow{3}{*}{ Bottom } & Back 7 & SST & 0.00 & 0.00 & 0.00 & 0.00 & 0.00 \\
\cline { 2 - 8 } & Left 8 & SST & 0.00 & 0.00 & 0.00 & 0.00 & 0.00 \\
\cline { 2 - 8 } & Right 9 & SST & 0.00 & 0.00 & 0.00 & 0.00 & 0.00 \\
\hline
\end{tabular}

Notes:

All table values have a relative uncertainty band $(1 \sigma)=2.5 \%$. 


\section{CONCLUSIONS}

The ability to accurately predict WG-MOX fuel pellet power profile, burnup, and isotope depletion profile is essential to evaluate the MOX fuel performance. Important neutronics parameters were computed using MCWO methods. This report utilizes the MCWO method to predict the needed neutronics parameters. The neutronics analyses include detailed radial fission and actinide reaction tallies in the fuel pins.

In this study, a detailed WG-MOX fuel test assembly model was developed. The model was validated by comparing the MCNP-calculated neutron fluxes with the flux-wire measurement data. There is excellent agreement between the MCNP-calculated results and the measured data. The validated WG-MOX fuel test assembly model was also used in the MCWO fuel burnup analyses, which provided the fuel burnup prediction during the irradiation Cycle $115 \mathrm{C}$ to Cycle $132 \mathrm{C}$.

\section{REFERENCES}

1. J. BRIESMEISTER (Editor), "MCNP-A General Monte Carlo N-Particle Transport Code, Version 4C," LA-13709-M, Los Alamos National Laboratory (2000).

2. A. G. CROFF, "ORIGEN-2: A Versatile Computer Code for Calculating the Nuclide Compositions and Characteristics of Nuclear Materials," Nuclear Technology, Vol. 62, pp. 335-352, 1983.

3. G. S. CHANG and J. M. RYSKAMP, "Depletion Analysis of Mixed Oxide Fuel Pins in Light Water Reactors and the Advanced Test Reactor," Nucl. Technol., Vol. 129, No. 3 , p. 326-337 (2000).

4. G. S. CHANG, " MCWO - LINKING MCNP AND ORIGEN-2 FOR FUEL BURNUP ANALYSIS," The Monte Carlo Method: Versatility Unbounded In A Dynamic Computing World, Chattanooga, Tennessee, April 17-21, 2005, on CD-ROM, American Nuclear Society, LaGrange Park, IL (2005).

5. G. S. CHANG, JW ROGERS, and J. M. RYSKAMP, "Neutron Flux and Spectrum Variation in a MOX Fuel Experiment," Trans. Am. Nucl. Soc., Vol. 81, 284 (1999).

6. R. N. MORRIS, C. A. BALDWIN, B. S. COWELL, S. A. HODGE, et. al. "MOX Average Power Early PIE: 8 GWd/MT Final Report," Oak Ridge National Laboratory, ORNL/MD/LTR-172, November 1999.

7. R. N. MORRIS, C. A. BALDWIN, S. A. HODGE, L. J. OTT, C. M. MALONE, N. H. PACKAN, "MOX Average Power Intermediate PIE: 21 GWd/MT Final Report," Oak Ridge National Laboratory, ORNL/MD/LTR-199, December 2000. 
8. R. N. MORRIS, C. A. BALDWIN, S. A. HODGE, N. H. PACKAN, "MOX Average Power 30 GWd/MT PIE: Final Report," Oak Ridge National Laboratory, ORNL/MD/LTR-212, November 2001.

9. R. N. MORRIS, C. A. BALDWIN, S. A. HODGE, N. H. PACKAN, "MOX Average Power 40 GWd/MT PIE: Final Report," Oak Ridge National Laboratory, ORNL/MD/LTR-241, Volume 1, August 2003.

10. B. S. COWELL AND S. A. HODGE, "ATR Capsule Assembly Loading and Operation Schedule," Oak Ridge National Laboratory, ORNL/MD/LTR-91, Rev. 4, November 2001. 